\title{
COVID-19 and Adoption of Webinars : Empirical Perspectives from Nigerian Small and Medium Enterprises
}

\author{
O. Bello"1, O.A Yahaya ${ }^{2}$ \\ ${ }^{*}$ Polytechnic Programmes Department, National Board for Technical Education, Kaduna, Nigeria \\ ${ }^{2}$ Department of Accounting and Management, Nigerian Defence Academy, Kaduna, Nigeria
}

\begin{abstract}
Article Info

Volume 8 Issue 2

Page Number: 264-278

Publication Issue :

March-April-2021

\section{Article History}

Accepted : 05 April 2021

Published : 11 April 2021

This study examines the factors driving the adoption of webinars among small and medium enterprises (SMEs) in the midst COVID-19 pandemic to hold meetings, training events and sharing business ideas and information. The study used survey questionnaires to obtain data from respondents based on a modified Unified Theory of Acceptance and Use of Technology (UTAUT) model. Results of the regression analysis show that performance expectancy is the most important determinant of webinar adoption during the COVID-19 pandemic. Based on the findings of the study, it is deduced that SMEs adopted webinars due to their perception that it improves their performance, increases their social status, adapts easily with their existing infrastructures and gives them positive feelings of pleasure and achievements.

Keywords : Coronavirus, Effort expectancy, Facilitating conditions, Performance expectancy, Social influence
\end{abstract}

\section{INTRODUCTION}

The outbreak of Coronavirus disease (COVID-19) in the later part of 2019 has led to unprecedented social, economic, and health catastrophe for the entire world. COVID-19 was reportedly broke out from Wuhan, China, then transmitted across the China and exported to other countries of the world by migrants. COVID-19 is caused by a novel severe acute respiratory syndrome coronavirus 2 (SARS-CoV-2). COVID-19 is transmitted through respiratory droplets or close person-to-person contacts with infected patients [1]. As at the end of February 2021, the number of confirmed cases across the globe was $113,950,840$ [2]. These figures continue to increase exponentially and it is very hard to determine the exact number of persons infected by the virus.

COVID-19 patients often show mild to severe respiratory and gastrointestinal symptoms such as pneumonia, fever, sore throats, nausea, headaches, fatigue, cough, diarrhoea and rhinorrhea. Patients with suspected symptoms of Coronavirus are subjected to reverse-transcription polymerase chain reaction (RT-PCR) to test their statuses. Positive test results of RT-PCR show that the patient is likely to have COVID-19 while negative test results means the patient is not infected. COVID-19 patients are usually managed through supportive therapy strategies including contact tracing and testing, hospitalization, public isolation therapy, intensive care unit treatment, 
mechanical ventilation or oxygenation support especially for persons with underlying health problems or low immune systems [3].

This pubic and global health challenge has disrupted human lifestyles and affected our conditions of living. The pandemic has caused serious disruption to most countries of the world. There were lockdown and quarantine orders, restricted border movement and inter-state travel bans instituted by different countries to mitigated community transmission of the disease. The impact of the pandemic differs from countries to countries. There is no standard and global approach to the pandemic. Thus, each country either develops or adopts suitable response based on their expertise, resources and ingenuity to address the crisis $[1,3]$. The net effect of the pandemic includes economic recessions and downturns, overstretched health care facilities, depleted medical supplies and consumables, food insecurity, mandatory shut down of schools, worship and public places, postponement of sporting and events, bankruptcy of firms, job and income losses, mental health crises and rising cases of gender-based or domestic violence, and increased public expenditure of Governments due to pandemic emergency response to provide aid, relief and economic security $[3,4]$.

In order to contain the spread of the pandemic and mitigate the global impact of COVID-19, the following non-pharmaceutical measures and guidelines were issued by World Health Organisation (WHO) and local Diseases Control agencies: regular hand washing using soap or alcohol-based sanitiser; wearing of face masks in the public; avoid touching mouth, eye and nose (MEN) with dirty hands; coughing and sneezing into tissue papers or elbows; screening of persons by temperature scanners; seeking and adhering strictly to medical advice; maintaining physical distance in the public of at least $1 \mathrm{~m}$; self isolation when having contact with infected patients; stay informed and stay at home if possible.
With recent developments in producing and administering of COVID-19 vaccines which have become an absolute necessity, especially to the persons who are most vulnerable to the disease, there is hope in sight that there would be lower incidences of fatality in the near future. This goal can be attained, when there is collaboration among public, private and non-government organisations to pool their resources together to produce the vaccines in large quantities in order to protect the entire global community from the deadly Coronavirus pandemic $[1,5,6]$.

However, one of the positive impacts of the COVID19 pandemic is that it offers every nation opportunities to learn what can be done to manage future responses, and also apply technological innovations to address novel challenges during a period of global crisis. For instance, surveillance systems were deployed to detect new cases of infection, telemedicine was used by doctors to attend to patients, social and electronic media were accepted to share information and knowledge across every strata of mankind $[3,6,7]$. COVID-19 pandemic has led to the use of online approaches by organisations, associations, religious groups, institutions and individuals to communicate or share information with each other using webinars. The use of smartphones or computers with relevant application software and stable internet connection have contributed significantly to contain the spread of the virus, reduce human-to-human contacts, improve convenience and conserve travel time and resources of users [8].

Webinars attracted more attention recently due their ability to connect users that are geographically separated by using shared virtual platform in realtime. Webinar is an online or Internet based technology where one or more facilitators can present lectures, hold interactive seminars, conduct conferences, organize training for a group of participants who are geographically separated in real 
time [3]. Webinar is an emerging technology to share information, facilitate discussions and deliver messages anytime and anywhere. Webinar can be regarded as a web-based seminar delivered over the Internet. It is an interactive technology that enables users to transmit, receive, demonstrate and discuss on various subjects of interest [5]. A webinar allows participants to join and interact in a platform through the use of real time video, voice or chat. Power point presentation, surveyor polls, interactive discussion, meetings can be conducted on a Webinar. Through webinar, live lectures delivered via the internet can reach a larger audience without location restrictions [9].

Platforms resources such as Facetime, GoToMeeting, Dyknow, Zoom, iLinc, Skype, Elluminate Live, Doxy.me, Adobe Acrobat Connect, Blackboard Collaborate, Wimba Classroom, Updox, Vsee, Pruffme, WebEx and Google Hangouts meet among others provide webinars services to users. These platforms have facial audio and visual components. These platforms are used with internet enabled smartphones, desktop, laptop or tablet computers. These applications enable multiple guests to participate in the conversations [7]. They enable face-to-face interaction between the users through an enriched virtual medium in real-time and just-in-time opportunities [8]. Webinar sessions can be simplex or one-way communication, from the presenter to the audience, or full duplex, two-way communication, the presenters and the participants can interact with each other through text, audio and web camera device [10].

There are two types of these online methods. These are asynchronous and synchronous technologies. An asynchronous technology allows users to learn activities at will or at any time or at their own pace. Asynchronous technologies do not support live interaction [8]. Synchronous technologies allow users to hold interactive at real time. They support real- time communication and virtual interactive sessions. Synchronous technologies require both the facilitator and the participants to be present at the same time for discussion or information dissemination to take place. An example of synchronous technologies is webinar $[9,10]$. Embedded functionalities of common webinar tools includes: desktop and application sharing, host or moderator control, HD video and audio, private and group chat, raise hand, recording, telephone callin, group collaboration, breakout rooms, keyboard control, screen sharing whiteboard [8].

Webinar is introduced across the globe, but the extent of implementation differs significantly from country to another in different ways, considering their perceived usefulness. Webinar is however associated with challenges that limit its effectiveness and efficiency. These include different level of proficiency among users, non-availability of high speed and high quality Internet connectivity, technical glitches, distractions, group size, motivational and psychological challenges of the users $[8,11]$. In order to maximize learning and engagement when using webinars, the facilitators need to carefully and properly design them to address or meet the audience's expectations, adequately plan and prepare the details of the presentations and evaluate them effectively using feedback survey [12].

Some of the merits of webinars include easy accessibility for users, affordability, attendees' participation and interaction, store recorded sessions in accessible achieves, immediate feedback, travel time and expenses are cut down significantly, time saving for organisations to hold meetings with their employees, suppliers and customers, flexibility, realtime dissemination of knowledge and information, and ease of mobility and usage. Webinars are more useful when they stir up interactions and active participation of the audience by the presenter(s). For instance, this type of interaction enables customers and employees of organisations to ask questions and 
contribute to the development of their organizations. It enables firms to improve on their products and services in addition enhancing their creditability [8, $11]$.

Recently, there is a substantial upsurge in the application of webinars by businesses, education and training institutions, health care service providers, financial service provider, religious organisations and engineering firms to deliver training courses, hold seminars, workshops and conferences with their clients, suppliers, customers, employees and the general public. Despite the increased acceptance of webinars as media of sharing knowledge and information especially during the COVID-19 restrictions, there are few studies in the literature that assess the factors that drive its adoption. Thus, empirical research studies investigating webinars in the context of users' acceptance during the global health challenges are scare.

The paucity of these studies is a huge knowledge gap that needs to be addressed because more comprehensive information about the factors that influence adoption of webinars would enable prospective SMEs to utilize webinars to meet the expectations of their customers and employees, and improve their credibility, competitiveness and effectiveness. Hence, it becomes desirable and important to identify and determine the factors that influence adoption of this technological innovation during COVID-19 pandemic. This study thus contributes empirically to identify the salient drivers of webinars that would help SMEs increase their profits and keep their business going and growing while adhering to COVID-19 safe protocol and practices $[9,13]$.

The paper is organized as follows: Section I contains the introduction of the study, section II explains the methodology of the study with the conceptual framework, and model specifications, section III presents the results and discussion of the findings and section IV concludes research studies with future directions.

\section{METHODS AND MATERIAL}

\section{A. Conceptual Framework}

A modified Unified Theory of Acceptance and Use of Technology (UTAUT) model proposed by [14] is adopted for this study. The model assists to understand the determinants of technology acceptance in order to create management interventions and inspire users who may be less willing to adopt and use new technology-based systems [15]. Fig. 1 shows the conceptual model of the modified UTAUT model adopted for this study.

1) Performance expectancy: According to [14, 19], performance expectancy is regarded as the degree to which an individual believes that using a new system or innovation will help him or her to attain gains in job performance. Many studies found that performance expectancy influences adoption of technological innovation. In [16], factors affecting behavioural intention to adopt web-based information system among students and staff of Moi University, Kenya were investigated. The results showed that performance expectancy affected the behavioral intention to adopt the system. Furthermore, acceptance of e-learning management system in five Universities in Kenya was examined by [17]. The results of the study showed that performance expectancy influenced adoption of elearning management systems in the five Universities. In [18], the study found that performance expectancy has significant relationship with behavioral intention to use digital technologies among four groups of first year students in North West University, South Africa.

In this study, it is assumed that adoption of webinar is consequential to the conviction of the SMEs that it will help them to achieve gains in performing their 
businesses during the COVID-19 pandemic. Thus, this null hypothesis, performance expectancy has no significant influence on webinar adoption was formulated.

2) Effort expectancy: Effort expectancy is regarded as the degree of ease associated with the use of a new system or innovation [19]. In [20], a study on adoption of ICT in an Indian government organization was performed. The study found that effort expectancy had positive impact on the use of ICT. In another related study, the factors that determine the students' intention to accept and use ICT at the Methodist University College, Ghana was carried by [21]. The study showed that effort expectancy positively influenced ICT adoption by students for learning and research. A study of influence of effort expectancy on the intention to adopt electronic government in Oman was studied in [22]. The study found that effort expectancy had significant influence on employees' intention to adopt e-government. In [23], factors that influence the use of ICT among undergraduate students of Universities of Maiduguri and Ibadan for their studies were investigated. The results indicated that effort expectancy significantly predicted adoption and use of ICT among the undergraduate students.

In this study, adoption of webinar is assumed to be stimulated by the perceptions of users that the technology is very simple and easy to use when users adhere to non-pharmaceutical measures during the COVID-19 pandemic. Thus, this null hypothesis, effort expectancy has no significant influence on webinar adoption was formulated.

3) Social influence: Social influence is referred to as the degree to which an individual perceives the importance others believe he or she should use an innovation or new system [14]. In a study performed by [16] among students and staff of Moi University, Kenya, the results showed that social influence affected the students' behavioral intention to adopt web-based information system. The results of a related study in [22] showed that social influence had significant effect on employees' intention to adopt electronic government in Oman. However, factors influencing adoption of ICT as teaching tools by Saudi Arabian primary school teachers were investigated in [23]. The findings of the study showed that social influence had weak negative and insignificant relationship with the behavioral intention of the teachers to adopt ICT.

In this study, adoption of webinar is predicated on the premise that SMEs are influenced by the importance that their stakeholders attached to the use of the technology especially during the COVID-19 pandemic. Thus, this null hypothesis, social influence has no significant influence on webinar adoption was formulated.

4) Facilitating conditions: Facilitating conditions are defined as the degree to which an individual believes that an organisational and technical infrastructure exists to support the use of a new system. In [25], it was demonstrated that facilitating conditions positively influence users' intention to use mobile health services. A similar study by [17], showed that facilitating conditions influenced adoption of elearning management systems among Kenyan Universities. Facilitating conditions was found in [18] to have significant relationship with behavioral intention to use digital technologies among four groups of first year students in North West University, South Africa. In [26], it was found that facilitating conditions had insignificant effect on adoption of ICT among Chinese business owners.

In this study, it is assumed that there are organizational and technical facilities, resources and equipment to facilitate the adoption of webinars by SMEs' stakeholders during the pandemic, Thus, this null hypothesis, facilitating conditions have no 
significant influence on webinar adoption was formulated.

5) Self efficacy: Self-efficacy represents the belief of an individual about his ability to perform a specific task or job using a new innovation or system [19]. Self efficacy was found to have positive impact on the acceptance and use of ICT among University academic staff in [27].

In this study, it is conceptualised that adoption of webinar depends on the basic and even advanced skills, knowledge and abilities of users to operate and deploy the technology to communicate, disseminate information, market their products and hold meetings. Thus, this null hypothesis, self efficacy has no significant influence on webinar adoption was formulated.

6) Anxiety: Anxiety expresses the apprehension or fear an individual experiences when using a new system or innovation. It relates to users' general perceptions about use of innovation [19]. Anxiety is a strong negative emotional state can arise when the notion to adopt a technological innovation is nurtured and when interacting with it. These may include phobia, apprehension, discomfort, fear, anxious responses, frustration, confusion, anger among others [28]. A number of studies have provided evidences supporting a direct relationship between behavioural intention to adopt technological innovation and anxiety. A study by [26] showed that anxiety factor had insignificant effect on the adoption of ICT among Chinese business owners. In [27], the study showed that the behavioural intention of University academicians to accept and use ICT for teaching and learning. The findings of the study showed that anxiety about ICT adoption does have an impact on academic staff adoption and use of ICT.

In this study, the use of webinars is presumed to have some level of discomfort, fear, anxiety and fear especially for new users. In addition, when there are technical glitches, it affects webinar adoption during the COVID-19 pandemic. Thus, this null hypothesis, anxiety has no significant influence on webinar adoption was formulated.

7) Attitude toward using technology: Attitude toward using technology is defined as an individual's overall affective reaction to use a new system or innovation [14]. Previous studies showed that individual attitude toward using technology have a strong effect on intention to adopt technology. The factors affecting the acceptance of ICT and their effect on small business owners in two provinces of China was investigated by [26]. It was found that attitude toward using technology has positive correlation with the adoption of ICT. In a related study by [27], attitude toward using technology was found to influence the acceptance and use of ICT among academic staff.

In this study, attitude towards webinar by users is considered to influence its adoption during this COVID-19 pandemic. Thus, this null hypothesis, attitude toward using technology has no significant influence on webinar adoption was formulated. 


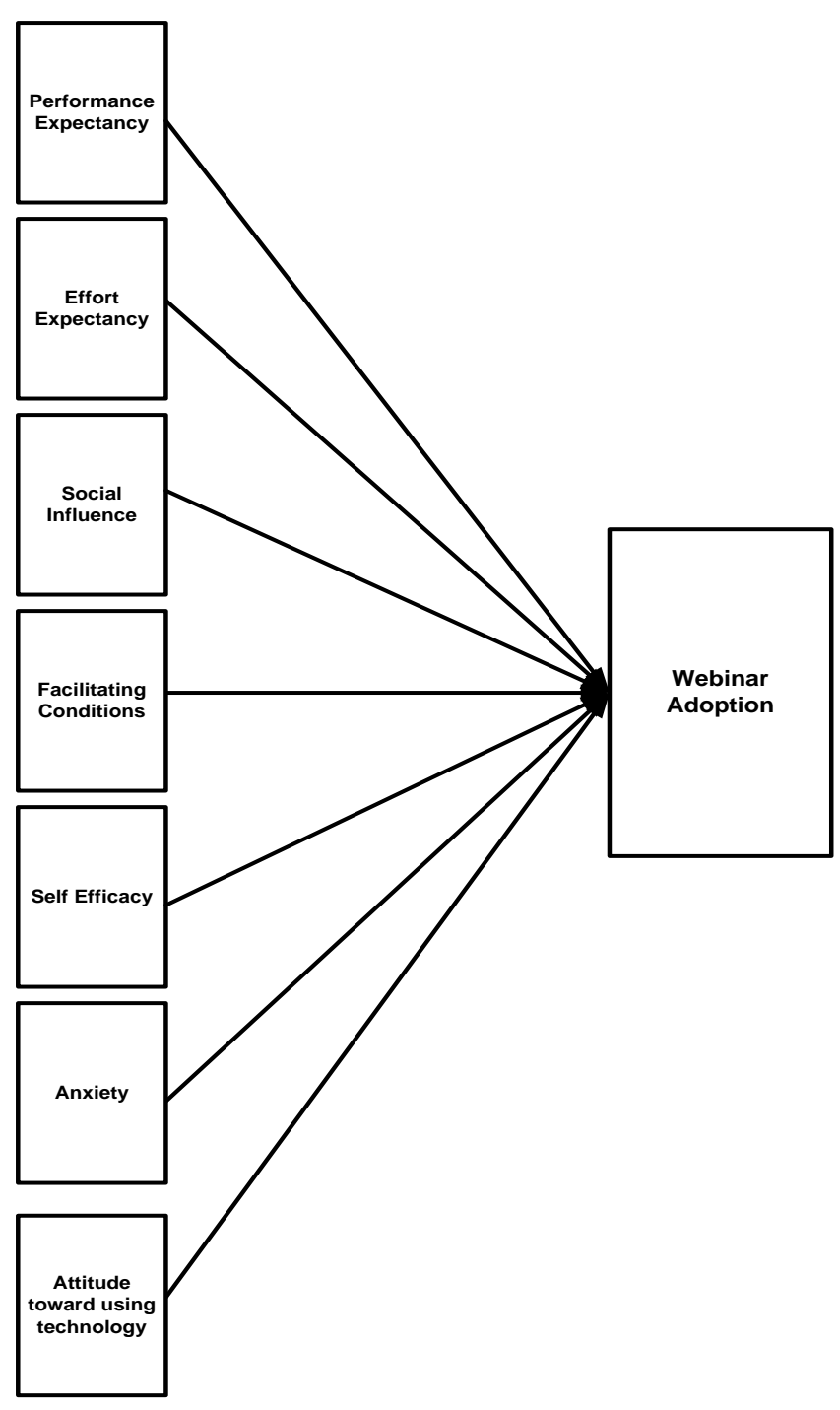

Fig. 1 Conceptual model of the study

\section{B. Data Collection}

Survey questionnaire was designed to obtain responses from SMEs in Nigeria. All questions stated in the questionnaire were linked to the key determinants in the conceptual model adopted for the study. Each statement in the questionnaire had multiple choices that the respondents would choose based on 5-level of Likert scale of agreement or disagreement. A total of 250 SMEs were contacted between the period of October, 2020 to January, 2021. In order to ensure fair representation, randomization method was used to administer the questionnaires.

A pilot study survey was conducted for 25 respondents $(10 \%$ of the SMEs population) for modification or improvement of the questionnaire before it was finally used to conduct the research study. After the pilot study and correction of the questionnaire, the main study was carried out. The data collected were processed, tabulated and analysed using Stata 13 statistical software package. A total of 250 questionnaires were distributed but only 200 questionnaires were successful filled and returned back. The response rate was $80 \%$.

\section{Model specification}

The model for this study is represented with the following regression equations:

$$
\begin{aligned}
& W A=f(\alpha+P E+E E+S I+F C+S E+A X+A U) \\
& W A_{i}=\alpha_{i}+\beta_{1} P E_{i}+\beta_{2} E E_{i}+\beta_{3} S I_{i}+\beta_{4} F C_{i} \\
& +\beta_{5} S E_{i}+\beta_{6} A X_{i}+\beta_{7} A U_{i}+e_{i}
\end{aligned}
$$

Where

$W A_{i}=$ Webinar adoption of $i^{\text {th }}$ observation

$P E_{i}=$ Performance expectancy of $i^{\text {th }}$ observation

$E E_{i}=$ Effort expectancy of $i^{\text {th }}$ observation

$S I_{i}=$ Social influence of $i^{\text {th }}$ observation

$F C_{i}=$ Facilitating conditions of $i^{\text {th }}$ observation

$S E_{i}=$ Self efficacy of $i^{\text {th }}$ observation

$A X_{i}=$ Anxiety of $i^{\text {th }}$ observation

$A U_{i}=$ Attitude toward using technology of $i^{\text {th }}$

observation

$\alpha_{i}=$ model constant of $i^{t h}$ observation

$e_{i}=$ error term of $i^{\text {th }}$ observation

$\beta_{1}, \beta_{2}, \beta_{3}, \beta_{4}, \beta_{5}, \beta_{6}, \beta_{7}=$ regression constants for each variable

\section{RESULTS AND DISCUSSION}

\section{A. Descriptive Statistics}

Table 1 showed the descriptive statistics for the variables of this study. The mean of performance expectancy was 4.070, minimum and maximum values were 1.377 and 5 , respectively. The standard 
deviation was 0.502 . It showed that the variations of performance expectancy values from the mean value were small. The mean of effort expectancy was 3.461, minimum and maximum values were 2 and 4.333, respectively. The standard deviation was 0.406 . It showed that the variations of effort expectancy values from the mean value were small. The mean of social influence values was 3.557, minimum and maximum values were 1.777 and 5, respectively. The standard deviation was 0.620 . It showed that the variations of the social influence values from the mean value were small. The mean of facilitating conditions values was 3.508, minimum and maximum values were 1 and 5, respectively. The standard deviation was 0.761 . It showed that the variations of facilitating conditions values from the mean value were small.

The mean of self efficacy values was 3.437, minimum and maximum values were 1.25 and 4.75 , respectively. The standard deviation was 0.757 . It showed that the variations of the self efficacy values from the mean value were small. The mean of anxiety values was 2.687, minimum and maximum values were 1 and 5 , respectively. The standard deviation was 1.083 . It showed that the variations of anxiety values from the mean value were small. The mean of attitude toward using technology values was 2.687, minimum and maximum values were 1 and 5 , respectively. The standard deviation was 0.686 . It showed that the variations of attitude toward using technology values from the mean value were small. The mean of webinar adoption values was 3.948 and minimum and maximum values were 1 and 5 , respectively. The standard deviation was .659. It showed that the variations of webinar adoption values from the mean value were small.

Table 1 Descriptive statistics of the variables of the study

\begin{tabular}{|l|l|l|l|l|l|}
\hline Var & Obs & Mean & $\begin{array}{l}\text { Standard } \\
\text { Deviation }\end{array}$ & Min & Max \\
\hline PE & 200 & 4.070 & .502 & 1.377 & 5 \\
\hline EE & 200 & 3.461 & .406 & 2 & 4.333 \\
\hline SI & 200 & 3.557 & .620 & 1.777 & 5 \\
\hline FC & 200 & 3.508 & .761 & 1 & 5 \\
\hline SE & 200 & 3.437 & .757 & 1.250 & 4.750 \\
\hline AX & 200 & 2.687 & 1.083 & 1 & 5 \\
\hline AU & 200 & 4.169 & .686 & 1 & 5 \\
\hline WA & 200 & 3.948 & .659 & 1 & 5 \\
\hline
\end{tabular}

B. Results of Diagnostic Tests

1) Correlation analysis: Table 2 shows the results of correlation analysis of the data used for the study. The correlation coefficient between performance expectancy and effort expectancy was 0.373. It showed a weak and positive association between the two variables. The correlation coefficient between performance expectancy and social influence was 0.420. It indicated a weak and positive relationship between the two variables. The correlation coefficient between performance expectancy and facilitating conditions was 0.356 . It showed a weak and positive relationship between the two variables. The correlation coefficient between performance expectancy and self efficacy was 0.396. It indicated a weak and positive association between the two variables. The correlation coefficient between performance expectancy and anxiety was 0.053 . It showed a very weak and positive association between the two variables. The correlation coefficient between performance expectancy and attitude toward using technology was 0.765 . It showed a moderate and positive association between the two variables. The correlation coefficient between performance expectancy and webinar adoption was 0.612. It indicated a moderate and positive relationship between the two variables.

The correlation coefficient between effort expectancy and social influence was 0.334 . It showed a weak and 
positive relationship between the two variables. The correlation coefficient between effort expectancy and facilitating conditions was 0.378 . It showed a weak and positive association between the two variables. The correlation coefficient between effort expectancy and self efficacy was 0.675. It indicated that a moderate and positive association between the two variables. The correlation coefficient between effort expectancy and anxiety was 0.294 . It showed a weak and positive association between the two variables. The correlation coefficient between effort expectancy and attitude toward using technology was 0.375 . It showed a weak positive association between the two variables. The correlation coefficient between effort expectancy and webinar adoption was 0.415 . It indicated a weak and positive association between the two variables. The correlation coefficient between social influence and facilitating conditions was 0.495 . It showed a weak and positive association between the two variables. The correlation coefficient between social influence and self efficacy was 0.264 . It showed that a weak and positive relationship between the two variables. The correlation coefficient between social influence and anxiety was 0.230 . It showed a weak and positive association between the two variables.

The correlation coefficient between social influence and attitude toward using technology was 0.5432 . It indicated a moderate and positive association between the two variables. The correlation coefficient between social influence and webinar adoption was 0.4232 . It showed a weak and positive relationship between the two variables. The correlation coefficient between facilitating conditions and self efficacy was 0.3031 . It showed a weak and positive association between the two variables. The correlation coefficient between facilitating conditions and anxiety was 0.0570 . It indicated a weak and positive association between the two variables. The correlation coefficient between facilitating conditions and attitude toward using technology was 0.5410 . It showed a moderate and positive association between them. The correlation coefficient between facilitating conditions and webinar adoption was 0.2194 . It showed a weak and positive association between the two variables.

The correlation coefficient between self efficacy and anxiety was 0.0075 . It showed a very weak and positive association between the two variables. The correlation coefficient between self efficacy and attitude toward using technology was 0.4105 . It showed a weak and positive relationship between the two variables. The correlation coefficient between self efficacy and webinar adoption was 0.4650. It showed that a weak and positive relationship between the two variables. The correlation coefficient between anxiety and attitude toward using technology was 0.0095. It showed a very weak and negative association between the two variables. The correlation coefficient between anxiety and webinar adoption was 0.0125 . It showed a very weak and positive relationship between the two variables. The correlation coefficient between attitude toward using technology and webinar adoption was 0.567. It indicated a moderate and positive association between the two variables.

From Table 2, it was observed that anxiety has very weak association with each of the independent and dependent variables. This showed that the variable needs further investigation using other diagnostic tests to determine whether to retain or eliminate the variable from the proposed model.

Table 2 Correlation matrix of the variables for the study

\begin{tabular}{|l|l|l|l|l|l|l|l|}
\hline $\begin{array}{l}\text { Va } \\
r\end{array}$ & PE & EE & SI & FC & SE & AX & AU \\
\hline PE & $\begin{array}{l}1.00 \\
0\end{array}$ & \multicolumn{7}{|l|}{} \\
\hline EE & $\begin{array}{l}0.37 \\
3\end{array}$ & $\begin{array}{l}1.00 \\
0\end{array}$ & & & & & \\
\hline SI & 0.42 & 0.33 & 1.00 & & & & \\
\hline
\end{tabular}




\begin{tabular}{|l|l|l|l|l|l|l|l|}
\hline & 0 & 4 & 0 & \multicolumn{5}{|l|}{} \\
\hline FC & 0.35 & 0.37 & 0.49 & 1.00 & \multicolumn{3}{|l|}{} \\
& 6 & 8 & 5 & 0 & \multicolumn{3}{|l|}{} \\
\hline SE & 0.39 & 0.67 & 0.26 & 0.30 & 1.00 & \multicolumn{2}{|l|}{} \\
& 6 & 5 & 4 & 3 & 0 & & \\
\hline AX & 0.05 & 0.29 & 0.23 & 0.05 & 0.00 & 1.000 & \\
& 3 & 4 & 0 & 7 & 7 & & \\
\hline AU & 0.76 & 0.37 & 0.54 & 0.54 & 0.41 & - & 1.00 \\
& 5 & 5 & 3 & 1 & 0 & 0.009 & 0 \\
\hline W & 0.61 & 0.41 & 0.42 & 0.21 & 0.46 & 0.012 & 0.56 \\
A & 2 & 5 & 3 & 9 & 5 & & 7 \\
\hline
\end{tabular}

2) Multicollinearity test: The results of multicollinearity test are shown in Table 3. It was observed that the highest Variance Inflation Factor (VIF) and lowest Tolerance were 3.33 and 0.299857 respectively for attitude toward using technology and the lowest VIF and highest Tolerance were 1.27 and 0.7863 respectively for anxiety. The mean value of VIF was obtained as 2.12. The results showed that all VIF values were below 4 and tolerance values were above 0.2. It could be inferred from the results that the degree of multicollinearity in the data was very low [29].

Table 3 Results of multicollinearity test

\begin{tabular}{|c|c|c|}
\hline Variables & VIF & Tolerance \\
\hline $\mathrm{AU}$ & 3.33 & 0.299857 \\
\hline $\mathrm{PE}$ & 2.54 & 0.393415 \\
\hline $\mathrm{EE}$ & 2.33 & 0.428894 \\
\hline $\mathrm{SE}$ & 2.09 & 0.479006 \\
\hline $\mathrm{SI}$ & 1.67 & 0.599081 \\
\hline $\mathrm{FC}$ & 1.64 & 0.610730 \\
\hline $\mathrm{AX}$ & 1.27 & 0.786348 \\
\hline Mean VIF & 2.12 & \\
\hline
\end{tabular}

3) Reliability test: Table 4 shows the coefficients of reliability of all independent and dependent variables expressed as Cronbach's Alpha values. The reliability values range from 0.6968 to 0.8362 . Based on these reliability coefficients, it can be inferred that the instrument showed good reliability because Cronbach's Alpha value for each variable was more than 0.69. This was higher than the benchmark a reliability coefficient of 0.6 recommended in [29].

Table 4 Results of reliability test

\begin{tabular}{|l|l|l|}
\hline Var & Observations & Cronbach's Alpha \\
\hline PE & 200 & 0.71 \\
\hline EE & 200 & 0.72 \\
\hline SI & 200 & 0.71 \\
\hline FC & 200 & 0.73 \\
\hline SE & 200 & 0.73 \\
\hline AX & 200 & 0.84 \\
\hline AU & 200 & 0.69 \\
\hline WA & 200 & 0.72 \\
\hline
\end{tabular}

4) Validity test: The validity test was carried out using Kaiser-Meyer-Olkin (KMO) to measure of sampling adequacy and factor loading. The results of the validity test are shown in Table 5 . The KMO values for all the variables are more than 0.5 except anxiety that was 0.3332 . The factor loading for anxiety was found to be 0.1986 . Factor loading of other variables are more than 0.3 . It showed that the anxiety is not satisfactory as a variable for this study. It was thus eliminated from the model as one of the independent variables.

Table 5 Results of first validity test

\begin{tabular}{|l|l|l|}
\hline Variable & KMO & Factor loading \\
\hline PE & 0.7102 & 0.7648 \\
\hline EE & 0.6499 & 0.7137 \\
\hline SI & 0.8233 & 0.7007 \\
\hline FC & 0.7950 & 0.6909 \\
\hline SE & 0.6638 & 0.6759 \\
\hline AX & 0.3332 & 0.1986 \\
\hline AU & 0.6920 & 0.8349 \\
\hline
\end{tabular}

After removing the anxiety from the dataset, the validity test was again carried out on the data set to check if the results would provide a reliable statistical 
inference. Table 6 shows $\mathrm{KMO}$ values and factor loading of the dataset without anxiety variables. The results showed that the $\mathrm{KMO}$ values for all the variables are more than 0.5 . The factor loading of all variables are more than 0.3 . It shows that the dataset is now suitable for the study. The model is assumed to be stable and likely to produce statistically reliable results.

Table 6 Results of second validity test

\begin{tabular}{|l|l|l|}
\hline Variable & KMO & Factor loading \\
\hline PE & 0.7096 & 0.7712 \\
\hline EE & 0.7006 & 0.7004 \\
\hline SI & 0.8626 & 0.6924 \\
\hline FC & 0.7957 & 0.6947 \\
\hline SE & 0.7092 & 0.6822 \\
\hline ATUT & 0.6968 & 0.8461 \\
\hline
\end{tabular}

5) Heteroscedasticity test: The heteroscedasticity test also known as residual analysis was used to check or show whether the model is efficient and stable or not. In this study, statistical tests were performed to quantify the presence or absence of heteroscedasticity in the model. The results of Breusch-Pagan/CookWeisberg test for heteroscedasticity carried out is shown in Table 7.

Table 7 Results of heteroskedasticity

\begin{tabular}{|l|l|}
\hline $\begin{array}{l}\text { Breusch-Pagan / Cook-Weisberg test for } \\
\text { heteroscedasticity }\end{array}$ & \\
\hline Ho: Constant variance & \\
chi2 $(6)=12.58$ & \\
Prob $>$ chi2 $=0.0503$ & \\
\hline
\end{tabular}

The $p$-value was higher than a significance level of 0.05 . Therefore, the null hypothesis that the variance of the residuals is constant was supported. It is inferred that heteroscedasticity is not present in the model. The model is regarded as statistically stable.

6) Normality test: The normality test shows whether the data set used for a study is normally distributed or not. The Shapiro-Wilk test was used in this study to test the normality of the data. When $W$ value is small, then the sample is not normally distributed and vice versa. From the results in Table 8 , the $W$ value is 0.827. This value is high and indicated that our sample was normally distributed.

Table 8 Results of normality test

\begin{tabular}{|l|l|l|l|}
\hline Var & Obs & W & V \\
\hline res & 200 & 0.82704 & 25.803 \\
\hline
\end{tabular}

\section{Regression Analysis}

The results of the regression analysis using Stata 13 package is shown in Table 9. The results of the overall model and value of $\mathrm{R}$-square are stated in the Table 9. From the result of the regression analysis, $49.1 \%$ of the variance on ICT adoption can be explained by the predictor variables of performance expectancy, effort expectancy, social influence, facilitating conditions, self efficacy and attitude toward using technology.

Performance expectancy had regression coefficient $\beta$ of 0.4489 with a value of 4.17 and a $p$-value of 0.000 . These indicated that as performance expectancy increased by a unit, webinar adoption was positively influenced by 0.4489 units. Effort expectancy had regression coefficient $\beta$ of 0.1517 with a $t$ value of 1.28 and a $p$-value of 0.203 . These showed that as effort expectancy increased by a unit, webinar adoption was positively influenced by 0.1517 units. Social influence had regression coefficient $\beta$ of 0.1994 with a $t$ value of 2.90 and a $p$-value of 0.004 . These indicated that as performance expectancy increased by a unit, webinar adoption is positively influenced by 0.1994 units.

Facilitating conditions had regression coefficient $\beta$ of -0.1694 with a $t$ value of -2.97 and a $p$-value of 0.003 . These showed that as facilitating conditions increased by a unit, webinar adoption was negatively influenced by 0.1694 units. Self efficacy had 
regression coefficient $\beta$ of 0.1706 with a $t$ value of 2.71 and a $p$-value of 0.007 . These indicated that as self efficacy increases by a unit, webinar adoption was positively influenced by 0.1706 units. Attitude toward using technology has regression coefficient $\beta$ of 0.1865 with a $t$ value of 2.09 and a $p$-value of 0.038 . These indicated that as attitude toward using technology increased by a unit, webinar adoption was positively influenced by 0.1865 units.

Table 9 Results of the regression analysis

\begin{tabular}{|l|l|l|l|l|}
\hline Var & $\begin{array}{l}\text { Coefficie } \\
\mathrm{nt}\end{array}$ & $\begin{array}{l}\text { Standard } \\
\text { Error }\end{array}$ & $\mathrm{t}$ & $\mathrm{P}(\mathrm{t})$ \\
\hline $\mathrm{PE}$ & .4489 & .1077208 & 4.17 & 0.000 \\
\hline $\mathrm{EE}$ & .1517 & .1187139 & 1.28 & 0.203 \\
\hline $\mathrm{SI}$ & .1994 & .068676 & 2.90 & 0.004 \\
\hline $\mathrm{FC}$ & -.1694 & .0570327 & -2.97 & 0.003 \\
\hline SE & .1706 & .0629005 & 2.71 & 0.007 \\
\hline AU & .1865 & .0893612 & 2.09 & 0.038 \\
\hline $\begin{array}{l}\text { cons } \\
\mathrm{t}\end{array}$ & .1107 & .3616381 & 0.31 & 0.760 \\
\hline R-squared $=0.4916$ & Adj R-squared $=0.4731$ \\
\hline
\end{tabular}

\section{Discussions of Findings}

1) Performance expectancy and webinar adoption: The first hypothesis of this study is that performance expectancy has no significant influence on webinar adoption. The results of hypothesis test showed that adoption of webinar is statistically influenced by performance expectancy. The $p$-value of performance expectancy was 0.0000 and less than 0.05. Therefore, the null hypothesis was rejected. Specifically, the study implied that most of the respondents assumed that the performance expectancy significantly improved webinar adoption during COIVD-19 pandemic. The results provided strong evidence that in order to maximize the adoption and usage of webinar, it is very important to provide adequate opportunities for SMEs to learn the capabilities of webinar and understand how it can improve their performance, productivity, profitability and competitiveness on their business activities. The finding of the study is consistent with the prior studies conducted by $[16,18,30]$.

2) Effort expectancy and webinar adoption: Another hypothesis formulated was that effort expectancy has no significant effect on webinar adoption. This result showed that webinar adoption is not directly affected by effort expectancy. The $p$-value of effort expectancy was 0.203 and greater than 0.05 . The results supported the null hypothesis formulated for this study. The result showed that webinar adoption is not statistically influenced by effort expectancy during the COVID-19 pandemic. The result might be as a result of the fact that most of the SMEs perceived webinar as difficult to understand and use. It could also be deduced that they considered accepting and using webinar might required special and technical skills which are rare. In addition, SMEs perceived that webinars might take longer time and more effort to learn and use. This result is consistent with a study by [31]. However, results from the studies in [20]-[22] showed that effort efficacy is an important determinant of adoption of technological innovations.

3) Social influence and webinar adoption: Social influence has no significant impact on webinar adoption was another hypothesis formulated for this study. The results of the analysis showed that social influence significantly affects webinar adoption. The $p$-value of social influence is 0.004 and is less than 0.05. Therefore, the null hypothesis was rejected. It means that social influence has significant impact on webinar adoption. In order to support and maximize the benefits of webinar adoption, it is crucial that the SME decision makers should recognize and pay attention to the importance of culture, image, status and norms as they positively affect webinar adoption in their firms. These results are consistent with the prior studies conducted by [16, 20, 21, 22, 25, 27, 31]. 
4) Facilitating conditions and Webinar adoption: One of the hypotheses formulated for this study is that facilitating conditions have no significant effect on webinar adoption. The $p$-value of facilitating conditions was 0.003 and less than 0.05 . Therefore, this hypothesis was rejected. The results showed that facilitating conditions have positive impact on webinar adoption during the COVID-19 pandemic. It suggests that the organizational and technical infrastructures of the SMEs play significant role in the rapid adoption of webinars during the pandemic. In addition, this shows that the adoption of webinars by SMEs is consistent with their existing values, needs and expectations. These results are consistent with the prior studies conducted by [18, 22, 25].

5) Self efficacy and webinar adoption: Another hypothesis of this study is that self-efficacy has no significant influence on webinar adoption. This hypothesis proposed that webinar adoption is not directly influenced by self efficacy. The $p$-value of self efficacy was 0.007 and less than 0.05 . Therefore, the null hypothesis was rejected. The results showed that self efficacy statistically influences adoption of webinars. It means that the confidence in the abilities of the SME owners to use webinars contributed to the adoption of webinars during this COVID-19 global challenge. The results of the study agreed with the findings in [27].

6) Attitude toward using technology and webinar adoption: The hypothesis that attitude toward using technology has no significant impact on webinar adoption was tested. The results of the tests showed that the attitude toward using technology significantly affects webinar adoption. The $p$-value of attitude toward using technology was 0.038 and less than 0.05 . Therefore, the null hypothesis was rejected. The results suggest that the feelings of joy, pleasure and excitement among SME owners and managers prompted the adoption of webinars during the
COVID-19 pandemic. These results are consistent with the prior studies conducted by $[26,27]$

\section{CONCLUSION}

The main focus of this study is to identify the factors that influence rapid adoption of webinars using a modified UTAUT model especially during the COVID-19 pandemic. The study found that performance expectancy is the most important determinant of webinar adoption among Nigerian SMEs. It implies that performance expectancy was the critical factor that influenced SMEs in Nigeria to adopt webinars to keep in touch with their employees, customers, suppliers and other important stakeholders during the pandemic. The results also revealed that social influence, attitude toward using technology and self efficacy have significant influence on webinar adoption.

However, the study showed that effort expectancy has no significant influence on webinar adoption. The implication of this finding is that Nigerian SMEs believed that adoption webinar to share information, organize training or holding meetings requires high level of computer proficiency and difficult to acquire. Based on the findings of the study, it can be inferred that the determinants of webinar adoption among SMEs in general can be determined when a suitable model is used to evaluate the key variables.

Future studies might be focussed on other models apart from the modified UTAUT model used in this study to identify other key factors that are likely to influence adoption of webinars among SMEs in Nigeria during or after the COVID-19 pandemic.

\section{REFERENCES}

[1]. F. Di Gennaro, D. Pizzol, C. Marotta, M. Antunes, V. Racalbuto, N. Veronese and L. Smith, "Coronavirus diseases (COVID-19) current status 
and future perspectives: a narrative review." International Journal of Environmental Research and Public Health, vol. 17, no. 9, pp. 2690-2698, 2020.

[2]. Johns Hopkins Coronavirus Resource Center (2021). COVID-19 Data in motion. Retrieved from https://coronavirus.jhu.edu

[3]. K. Goniewicz, A. Khorram-Manesh, A.J. Hertelendy, M. Goniewicz, K. Naylor and F.M. Burkle, "Current response and management decisions of the European Union to the COVID19 outbreak: a review," Sustainability, vol. 12, no. 9, pp. 3838, 2020.

[4]. J.J. Cavallo and H.P. Forman, "The economic impact of the COVID-19 pandemic on radiology practices," Radiology, vol. 296, no. 3, pp. 141-144, 2020.

[5]. L. Corey, J.R. Mascola, A.S. Fauci, \& F.S. Collins, "A strategic approach to COVID-19 vaccine R\&D" Science, vol. 368, no. 6494, pp. 948-950, 2020.

[6]. V.J. Lee, C.J. Chiew, and W.X. Khong, "Interrupting transmission of COVID-19: lessons from containment efforts in Singapore," Journal of travel medicine, vol. 27, no. 3, taaa039, 2020.

[7]. A.J. Gadzinski, J.L. Gore, C. Ellimoottil, A.Y. Odisho and K.L. Watts. "Implementing telemedicine in response to the COVID-19 pandemic".

Available: https://www.auajournals.org/doi/pdf/10.1097/JU.0 $000000000001033,2020$.

[8]. P. Lieser, S.D. Taf and A. Murphy-Hagan, "The Webinar Integration Tool: A Framework for promoting Active Learning in Blended Environments," Journal of Interactive Media in Education, vol.1, no.7, pp. 1-8, DOI: https://doi.org/10.5334/jime.453, 2018.

[9]. H.H. Nadama, M. Tennyson, and A. Khajuria, "Evaluating the usefulness and utility of a webinar as a platform to educate students on a UK clinical academic programme," The Journal of the Royal College of Physicians of Edinburgh, vol. 49, no. 4, pp. 317-322, 2019.
[10]. R.L. Humphrey, C.S. LeGrand, and D.F. Beard, "How to host a successful webinar," Strategic Finance, vol. 95, no. 1, pp. 31-38, 2013.

[11]. Z.V. Smirnova, N.V. Kamenez, O. Vaganova, L.I. Kutepova \& E.V. Vezetiu, "The experience of using the webinar in the preparation of engineering specialists. Amazonia Investiga, vol. 8, no. 18, pp. 279-287, 2019.

[12]. N. Bedford Webinar best practices. 2016. Available: http://dx.doi.org/10.22215/cfice-201606

[13]. A. Gegenfurtner, A. Zitt, and C. Ebner, "Evaluating webinar-based training: a mixed methods study of trainee reactions toward digital web conferencing," International Journal of Training and Development, vol. 24, no. 1, pp. 521, 2020.

[14]. V. Venkatesh, M.G. Morris, G.B. Davis, and F.D. Davis, "User acceptance of Information Technology: Toward a unified view" MIS Quarterly, vol. 27, no. 3, pp. 425-478, 2003.

[15]. E. Korpelainen. Theories of ICT system implementation and adoption - A critical review, 2011.

Available: http://lib.tkk.fi/SCIENCE_TECHNOLOGY/2011/i sbn9789526041506.pdf.

[16]. K.P. Chumo, and D.K. Kessio, "Use of UTAUT model to assess ICT adoption in Kenyan Public Universities," Information and Knowledge Management, 5(12), 79-83, 2015.

[17]. K.M. Maina and D.M.N. Nzukim, "Adoption determinants of e-learning management system in Institutions of Higher learning in Kenya: A case of selected Universities in Nairobi Metropolitan," International Journal of Business and Social Science, 6(2), 233-248, 2015.

[18]. J. Liebenberg, T. Benade and S. Ellis, "Acceptance of ICT: Applicability of the Unified Theory of Acceptance and Use of Technology (UTAUT) to South African students", The African Journal of Information Systems, vol. 10, no. 3, pp. 1-15, 2018.

Available: htps://digitalcommons.kennesaw.edu/ajis/vol10/is s3/1 
[19]. V. Venkatesh and F.D. Davis, "A theoretical extension of the technology acceptance model: Four longitudinal field studies" Management Science, vol. 46, no. 2, pp. 186-204., 2000.

[20]. B. Gupta, S. Dasgupta and A. Gupta, "Adoption of ICT in a government organization in a developing country: An empirical study," Journal of Strategic Information Systems, no. 17, pp. 140-154, 2008.

[21]. S.N. Attuquayefio and H. Addo, "Using the UTAUT model to analyze students' ICT adoption," International Journal of Education and Development Using Information and Communication Technology, vol. 1, no. 3, pp. 7586, 2014.

[22]. M.N. Alraja, S. Hammami, B. Chikhi and S. Fekir, "The Influence of effort and performance expectancy on employees to adopt e-Government: evidence from Oman," International Review of Management and Marketing, vol. 6, no. 4, 2016.

[23]. A.M. Ibrahim, M.A. Adamu and M. Gujbawu, Analysis of the expectation of effort expended when ICT is used in academic learning activity: Influence of effort expectancy and moderating role of experience, MCC, vol. 1. No. 1, pp. 19-38, 2017.

[24]. Y. Sun, N. Wang, X. Guo, and Z. Peng, Understanding the acceptance of mobile health services: A comparison and integration of alternative models, Journal of Electronic Commerce Research, vol. 14. No. 2, pp. 183-200, 2013.

[25]. X. Jie, Q. Sadja and N. Lotfollah, Factors that affect Information and Communication Technology adoption by small businesses in China. Proceedings of the 19th Americas Conference on Information Systems, Chicago, United States of America, 2013. Available: https://pdfs.semanticscholar.org/3939/8b485351e9 adee22ba1ab55a7ffee

[26]. N.D. Oye, N. A. Iahad and N.R. Ab. Rahim, “The impact of UTAUT Model and ICT theoretical frameworks in University academic staff: Focus on Adamawa State University, Nigeria,"
International Journal of Computer and Technology, 2(2) 102-111, 2012.

[27]. S.L. Chua, D.T. Chen and A.F. Wong, "Computer anxiety and its correlates: a meta-analysis," Computers in human behavior, vol. 15, no. 5, pp. 609-623, 1999.

[28]. J.F. Hair, W.C. Black, A.L. Babin and R.L. Tatham, Multivariate Data Analysis. (6thed.). New Jersey Pearson: Prentice Hall, 2006.

[29]. K.J. Paul, M. Musa and A.K. Nansubuga, "Facilitating condition for E-learning adoptionCase of Ugandan universities", Journal of Communication and Computer, vol. 12, no. 5, pp. 244-249, 2015.

[30]. A. Ibrahim, M. Adu-Gyamfi and B.A. Kassim, "Factors affecting the adoption of ICT by administrators in the University for Development Studies, Tamale: Empirical evidence from the UTAUT Model" International Journal of Sustainability Management and Information Technologies, vol. 4, no.1, pp. 1-9, 2018.

[31]. S. Alshmrany and B. Wilkinson, "Factor influencing the adoption of ICT by teachers in primary schools in Saudi Arabia," International Journal of Advanced Computer Science and Applications, vol. 8, no. 12, pp. 143-156, 2017.

\section{Cite this article as :}

O. Bello, O. A. Yahaya, "COVID-19 and Adoption of Webinars: Empirical Perspectives from Nigerian Small and Medium Enterprises", International Journal of Scientific Research in Science, Engineering and Technology (IJSRSET), Online ISSN : 2394-4099, Print ISSN : 2395-1990, Volume 8 Issue 2, pp. 264-278, March-April 2021. Available at doi : https://doi.org/10.32628/IJSRSET218266 Journal URL : https://ijsrset.com/IJSRSET218266 